\title{
Shoots and leaves: exploring the impacts and fragile sustainability of sustainable place-making projects working with marginalised people
}

\author{
Sam Ramsden, sam.ramsden@hull.ac.uk \\ University of Hull
}

This article contributes to emerging research on sustainable place-making, but makes an important contribution through a strong focus on outcomes for marginalised people and the need for long-term sustainability. Sustainable place-making combines 'place-making' and 'sustainable development' to describe locally focused action working towards social, economic and environmental goals (Franklin and Marsden, 2015). The article explores an externally funded charity-led project working in a deprived area of the UK, implementing urban agriculture, community gardening and household energy activities. The project successfully engaged marginalised people, who strongly voiced outcomes including reduced isolation, improved mental health and increased resilience and self-reliance. Support from staff, volunteering in a team, enjoying gardening, accessing nature and financial savings provided a platform for impacts. Environmental outcomes were less tangible but included improvements to the local environment and reduced energy usage. However, after the funding finished, marginalised participants were vulnerable to outcomes not being sustained in the long term.

\section{Key words sustainable place-making $•$ long-term sustainability $\bullet$ marginalised people $•$ community gardening}

To cite this article: Ramsden, S. (2020) Shoots and leaves: exploring the impacts and fragile sustainability of sustainable place-making projects working with marginalised people, Voluntary Sector Review, vol 00, no 00, 1-17, DOI: 10.1332/204080520X15898294617450

\section{Introduction}

Hull is a city in the north of England that has high levels of deprivation (ONS, 2015; Porter et al, 2015). This article explores the case study of an externally funded charity-led project that supported marginalised people in Hull to engage in urban agriculture (UA) and community gardening, volunteering, and household energyefficiency activities, with broad aims to increase sustainable living, reduce poverty and improve the environment. The outcomes of the project are explored through the framework of sustainable place-making, which brings together 'place-making' and 'sustainable development' to analyse community-level sustainability-focused activities working towards social, economic and environmental goals (Franklin and 
Marsden, 2015). Sustainable place-making includes UA, community gardening and community-level energy activities, which are increasing in the UK and globally (Holland, 2004; Crane et al, 2013; Franklin and Marsden, 2015). The article aims to strengthen emerging research on sustainable place-making by focusing on the long-term sustainability outcomes for marginalised people, which are sometimes overlooked in existing research. The article first explores the concept of 'sustainable place-making' before then presenting the research, including a description of the case study context and the research methods used. The article then explores outcomes for marginalised people in the case study through the stories of five participants and by tracking what happened to the activities after the project ended. The article then makes recommendations for policy and practice. Critically exploring the outcomes and challenges of sustainable place-making projects in a deprived area can provide important lessons for the growing number of other similar projects.

\section{Exploring sustainable place-making}

There is a need to develop healthy and sustainable cities to tackle the growing pressures from increasing urbanisation and the impacts of climate change (van den Bosch and Sang, 2017). Cities are places of inequality and marginalisation (Milbourne, 2012) and Heynen et al (2006:2) describe how 'the city is the place where socio-environmental problems are experienced most acutely'. Horlings (2015:258) argues that healthy and sustainable cities can be created through the development of 'place-based approaches'. Place-making is an active process, described by Pierce et al (2011:54) as the 'set of social, political and material processes by which people iteratively create and recreate the experienced geographies in which they live ... Place-making is an inherently networked process, constituted by the socio-spatial relationships that link individuals together through a common place-frame'. There is a strong connection between place-making and improving access to green and natural spaces (Dale et al, 2008). For example, improving local parks, tree planting and UA activities are increasingly important place-making activities (Holland, 2004; Franklin and Marsden, 2015; Mathers et al, 2017) and are especially important in cities, which can suffer from a lack of access to nature and greenspaces (Milbourne, 2012). For example, Certomà and Tornaghi (2015: 1123) comment on how increasing UA and community gardening support place-making in cities:

[I]n the last decade, a large variety of grassroots actors - urban harvesters, guerrilla gardeners, community growers and landsharers - have been promoting a diversified set of projects that, while interstitial and very often considered 'residual' are nonetheless significantly challenging the placemaking of cities in the Global North, and sometimes changing the face of neighbourhoods where they are located.

Beilin and Hunter (2011:523) develop the important link between place-making and sustainability and argue that "community garden activities are frequently described as contributing positively to the development of socially and environmentally sustainable local communities'. UA and community gardening can help create healthy, socially and environmentally sustainable communities through improving health and wellbeing, developing skills and confidence, and reducing isolation (Ferris et al, 2001; Holland, 
2004; Miller, 2015). Pitt (2014) describes the therapeutic benefits of gardening for older people and people with mental health problems, including through enjoying the different tasks of gardening and reducing isolation. Baker (2004) and Jean (2015) research place-making by refugees and newly arrived immigrants involved in UA activities, many of whom are escaping conflict and trying to adapt to a new country. Jean (2015:56) argues that 'a sense of place comes from having the ability to participate in place-making activities that develop a connection to landscape, soil, and the physical environment'. Enjoyment of gardening, access to nature and working with others encourage participation in the growing number of activities (Bhatti et al, 2009; Pitt, 2014; Jean, 2015).

Community-level energy projects can also be considered as sustainable place-making activities (Franklin and Marsden, 2015; Parkhill et al, 2015) and the numbers of projects are also increasing (Seyfang et al, 2013). Community-level energy projects can involve both technologically focused projects such as generating renewable electricity through installing solar panels, and also approaches to increase energy literacy, reduce energy consumption and reduce energy costs (Stephenson et al, 2010; Seyfang et al, 2013; Parkhill et al, 2015). However, there is less in-depth research into the impacts of energy projects on marginalised people compared with UA and community gardening, potentially because many community-level energy projects work at a household level rather than in a public space and can have limited ongoing contact with participants (Hargreaves et al, 2010). A range of research suggests that there are possibilities for community-level energy projects to reduce vulnerability to fuel poverty (Seyfang et al, 2013; Parkhill et al, 2015) and Lorenc et al (2013) describe a charity-led project that helped vulnerable people to reduce their energy bills through advice on tariffs. Reducing energy costs for people vulnerable to fuel poverty in deprived areas is also argued to increase community resilience (Parkhill et al, 2015). Resilience is a broad and contested term, but can be described as households or communities being able to overcome shocks or ongoing serious challenges, or even improve their situation (Parkhill et al, 2015; Dagdeviren et al, 2016).

The literature describes many health and social benefits of sustainable placemaking activities, including reduced isolation, improved mental health and reduced vulnerability to poverty. However, there is criticism of exaggerating the benefits of sustainable place-making activities without critically analysing negative impacts and challenges (Ferris et al, 2001; Tornaghi, 2014; Miller, 2015). Long-term sustainability is often fragile as many projects are led by charities that rely on external funding, and obtaining external funding is increasingly challenging (Seyfang et al, 2013; White and Stirling, 2013; IVAR, 2016). Seghezzo (2009) describes the importance of 'permanence' in sustainable development but how this is often neglected in planning. Planning for sustainability is not possible for many projects operating on three-year funding cycles and in an insecure funding environment (IVAR, 2016). Without charity-led interventions, activities can be dominated by more middleclass participants and develop in more affluent communities (Chatterton and Cutler, 2008; Aiken, 2012; Franklin and Marsden, 2015), reducing participation by marginalised people. A further criticism is that external support for community-level projects enables the further rollback of the state, particularly in the UK, which has seen public spending cuts through the government's austerity agenda. For example, Tornaghi (2014:3) identifies that UA can help justify the 'privatisation of the urban realm and disinvestments in disadvantaged areas' such as through cuts to health and 
wellbeing services, and public space management. For instance, community gardens are criticised for substituting professional care for community care for people with mental health issues (Ferris et al, 2001; Tornaghi, 2014). In addition, Mathers et al (2017) suggest that many community-level activities, such as supporting local libraries to save them from closure, or maintaining public parks, should be considered 'placekeeping' rather than place-making. In addition, there is an increasing focus on the potential of community-level sustainability-focused activities to help tackle climate change (Holland, 2004; Pearsall et al, 2012); however, Chatterton and Cutler (2008) question the scale of environmental impacts from community-level initiatives and whether they can make a difference. While it is argued that there are impacts from energy activities, UA activities and improved green spaces, in reducing global levels of carbon dioxide $\left(\mathrm{CO}_{2}\right)$, there is very little quantitative evidence (Hargreaves et al, 2010; Mason and Montalto, 2015).

Despite the criticisms and challenges, it is argued that sustainable place-making activities are happening on the ground and research can help support projects (Holland, 2004; Franklin and Marsden, 2015). In addition, there is a need to hear the voices of marginalised groups describe their own experiences, and this is particularly important in exploring whether projects can help strengthen community resilience in the face of serious challenges and shocks such as poverty, austerity and the impacts from the rollback of the state.

\section{Research context and methods}

\section{Research context: Hull and the case study project}

This article focuses on the case study of a Big Lottery Fund (BLF) project in Hull in northern England. The Big Lottery Fund was established by the National Lottery Act in 2006 and is 'responsible for distributing 40\% of all funds raised for good causes by the National Lottery' (Big Lottery Fund, 2018). The Green Prosperity (GP) project was a $£ 1$ million project running from 2013 to 2015 , led by a local charity and supported by two other local organisations. The BLF funded the GP project as part of the Communities Living Sustainably (CLS) funding stream, which supported 12 projects in deprived areas across the country to explore connections between climate change, sustainable living and poverty reduction and to achieve outcomes for vulnerable people (St Clair et al, 2017; Big Lottery Fund, 2018). CLS projects were established as 'test and learn' projects to explore what worked at a community level and to provide flexibility for projects. Funding of up to $£ 1$ million was provided for individual CLS projects over a period of three to five years, from 2014 to 2018 inclusive.

The GP project worked with communities in east Hull, a disadvantaged area in one of the most deprived cities in the UK. Hull has a population of approximately 260,000 and has experienced post-industrial decline, with high levels of unemployment after the reduction in North Sea fishing and dock labour (Atkinson, 2008; Jonas et al, 2016). At the time of the research in 2015, Hull was identified as the third most disadvantaged local authority area in the UK (ONS, 2015). It was estimated that $13 \%$ of Hull's residents lived in fuel poverty (Porter et al, 2015), and there was increasing evidence of food poverty (FareShare, 2015). Platt (2011) says that in Hull 'the worst poverty isn't found in the historic city centre, but on the estates on the 
outskirts' and areas of east Hull are considered as some of the most deprived parts of Hull. However, the story of decline and deprivation masks the resilience and positive agency in Hull. Hull has a strong sense of community and residents of Hull have demonstrated their resilience, overcoming severe bombing during World War Two and widespread flooding in 2007 (Starkey et al, 2017). Hull is an important historical city, a city of poetry, a city of sport and a city of culture (Starkey et al, 2017). Hull is also becoming a centre of the renewable energy industry through the Green Port Development. The council also has a history of being proactive in anti-poverty and food security projects, such as through the pioneering 'Eat Well Do Well' initiative in 2004 to improve nutrition in schools (Colquhoun et al, 2008). Hull also has a wide range of grassroots community gardening and food growing projects, and at the time of the research, it was actively working towards becoming a member of the 'Sustainable Food Cities' network (Sustainable Food Cities, 2017).

The local organisations that developed the GP project felt that the aims of the CLS funding stream were relevant to the local community and successfully obtained funding. The project plan included a number of sustainable place-making activities: UA, volunteering outreach, community energy, eco-enterprises and a 'green care' activity to support local carers. The UA activity became a strong focus and the project employed three members of staff with strong skills and experience and who were well connected to the wider food growing network in Hull. The main focus of the UA activities was to establishing a community garden at the East Hull Community Farm (EHCF), which allocated land to the project. The volunteer outreach activity also became embedded in the UA activities.Volunteers met weekly at the community garden and then provided support to additional activities including supporting local families to grow their own food (the family growing project) and other more ad-hoc activities including supporting a city-wide cooking event (the Feastival), tree planting in local schools and building bat and bird boxes. The UA activity also provided training courses for the wider community, including specific sessions aimed at fathers and children, and refugee families. The energy activity was developed separately from the UA and volunteering activities and was led by one member of staff. It focused on work at a household level and engaged residents through installing a free energy monitor and then used this visit to provide advice on identifying better tariffs, switching from pre-payment meters, which incur higher charges than payment by monthly direct debit, and the Warm Home Discount (WHD) - a government-supported grant to reduce costs for vulnerable people. However, the eco-enterprise and green-care activities did not begin work at a community level due to a range of governance issues.

\section{How the research was conducted}

The research contributed to monitoring and evaluation for the GP project and the main focus of the research was exploring outcomes for participants. However, the research did not include any financial or cost-benefit analysis. Measuring environmental impacts was also beyond the scope of the research. The research started in February 2014, approximately one year after the GP project began, and continued until one year after completion. The research focused on the UA, volunteering and community energy activities due to their engagement with participants. There was a focus on qualitative research and semi-structured interviews, with a flexible approach to explore themes from the stories and perspectives of participants and staff. This approach is 
Table 1: Interviews with participants and staff conducted, by activity

\begin{tabular}{|l|c|c|}
\hline & Interviews & Participants \\
\hline Operational staff (UA, volunteering and energy activities) & 9 & 6 \\
\hline UA - volunteers & 50 & 31 \\
\hline UA - participants & 19 & 11 \\
\hline Energy - participants & 40 & 40 \\
\hline
\end{tabular}

in line with Creamer's (2015: 987) approach to understanding local interpretations of sustainability and community by allowing 'themes to emerge unrestricted by preconceptions, frameworks and theories'. The length of the research was critical in developing trust and rapport with staff and participants. Continuing research for one year after project completion also enabled me to investigate project outcomes for marginalised people and governance issues and track long-term sustainability.

The embedded research role provided continuous access to participants during project activities, although I had more access to the UA participants than the household energy participants. I regularly attended the Wednesday sessions at the community garden, and the family growing project sessions, and built up relationships with the volunteers and families involved. In contrast, it was more difficult to build up relationships with people who only participated in the energy activities where the interaction between residents and the project was through a household visit, and there was minimal ongoing contact. Conducting follow-up interviews to identify outcomes was extremely difficult due to people changing contact information, particularly mobile phone numbers, and people not wanting to give up time to answer questions due to other priorities such as providing care or working.

Table 1 identifies the number of interviews conducted during this research. Some UA participants and volunteers were interviewed more than once to follow up themes or outcomes. In addition, there was some overlap, with eight UA participants also having energy monitors.

Due to the need for continuous feedback of findings to the project, interview recordings were transcribed on a continuous basis. Transcriptions and field notes were then coded and analysed to identify themes, which were continuously revised. For instance, as the research progressed and more trust and rapport was developed, some UA and community gardening participants were very open in describing how the project helped them address health and wellbeing issues or challenges obtaining state benefits, and I followed up on these themes in more detail through further interviews.

There were challenges and ethical dilemmas in the field especially in trying to be constructive and avoid emotional attachment, while providing support (Tornaghi and Van Dyck, 2015). For instance, there were tensions towards the end of the funding period when staff and participants were concerned about what would happen to them and the project activities without access to further funding. Many volunteers expressed how they did not feel able to continue their activities without staff support. For instance, one regular volunteer commented: "I think it's a shame, it's really sad. I know they've said this is the best year for volunteers and people getting involved and to cut it off at such an important stage, I think it's a shame, a lot of people are going to lose out."

Concerns about the future of the project affected my research in that I felt under pressure to produce research findings relatively quickly for the project to use as 
evidence of its impacts. This was particularly relevant for the energy project where I had less ongoing contact with participants. But this period also showed the reality of working with a charity-led project that was about to have its funding stopped.

\section{Research findings: examining whether sustainable place-making activities can lead to social, economic and environmental outcomes for marginalised people}

This section explores the outcomes of the different activities for marginalised people, focusing on the UA and community gardening, volunteering and community energy activities as the main activities that were implemented. The section also tracks the long-term sustainability of the project activities and how this affected the project participants. As the research progressed, volunteers and participants were often very open about the challenges they faced and how involvement in the project was helping them. However, participants also illustrated how these benefits were fragile by the end of the project in the face of continuous uncertainty. Stories from five participants have been selected as examples, with pseudonyms used. All five were participants of the UA activities and two also engaged in the energy activities.

\section{Exploring the benefits of being involved in the GP project}

The UA strand developed a wide range of activities to engage marginalised people, including establishing a community garden, and a strong team of local volunteers who wanted to give back to their community (Milligan and Fyfe, 2005; Franklin and Marsden, 2015). Two members of staff managed the community garden and volunteer outreach activities, approximately 120 volunteers committed nearly 5,000 hours across the different activities, and there were approximately 50 regular volunteers (although some left during the project). A large number of other participants became involved in the UA activities, which supported people to grow their own food, including 10 local families through the family growing project. Volunteers and participants strongly voiced how they enjoyed the range of activities and gardening in a supportive environment, with many volunteers also describing how the project brought back happy memories of gardening as children (Bhatti et al, 2009): "Yes, the only time I ever did this was when I was a child and we had gardening tasks to do as children so we could earn pocket money. Mum and Dad's garden was always full of gooseberries, raspberries, you name it they would grow it."

Volunteers and participants described a wide range of beneficial outcomes, including improved mental health, reduced isolation, the building of friendships, increased skills and confidence, and improved self-reliance. These benefits resonate with a wide range of research into UA and community gardening activities (Milbourne, 2012; Crane et al, 2013; Miller, 2015). Arthur and Tony were long-term volunteers and their stories illustrate some of these benefits. By the end of the project, Arthur had input nearly 400 volunteer hours for the project, working at the community garden, and supporting other UA activities including the family growing project and a 'Feastival'. Tony dedicated more than 150 hours to the same activities, except he was not able to attend the community garden. Both Tony and Arthur were unemployed and were frustrated at being stuck in their homes with nothing to do and with few 
volunteering opportunities before the GP project and both had enjoyed gardening before the project but had not done any gardening for a long time.

As a reward for their volunteering input, the GP project facilitated both volunteers to attend horticulture courses at the Hull College horticulture site, which was located in east Hull. It took a lot of hard work and dedication for them to progress through the course. Both started the course at an entry level due to their low levels of literacy. Tony had severe dyslexia but was very committed to improving his reading and writing. In the following quote, Tony identified how he would need to improve his reading to move to more advanced levels, but which he then succeeded in doing:

Interviewer: 'Would you like to move to the next level?'

Tony: 'I am going to try, but I can't read you see, so it will be a bit harder'.

Both Arthur and Tony said that staff at the Department for Work and Pensions (DWP) were supportive of their studying and volunteering, except Arthur said that volunteering and studying had helped his relationship with the DWP benefits staff. Before becoming involved with the GP project, he had received a benefit sanction, which resulted in him going to a foodbank, despite being 63 years old. Describing his first use of a food bank in 2014, he said: "I said to be myself I would never go to a food bank, but when I got sanctioned a couple of years ago, I got no grub in ... because they stop your money straightaway." However, since being involved in the project,Arthur stated:"I do this and I volunteer, and it keeps them off my back - they know I'm not sat at home - they know I'm doing summat, they don't hassle me."

Both Arthur and Tony really enjoyed the other volunteering activities, working as part of a team and giving back to their local community.
'I like doing all the gardening ... I enjoyed the eco-garden, planting trees at the school'. (Tony)
'I love helping people me, ... this lady's got a garden, the council nag her, to get it done, sent her a letter saying if she don't get it done ... she gets a lot of volunteers like us, spend a day on the garden, cleared it, dug it, it's beautiful.' (Arthur)

Arthur also used his gardening experience and learning to give advice, illustrating an increase in skills and confidence:
'Yes, yes, the old lady, she put some stuff in the garden and it dies, she uses the same part of the garden every year, and I said: "What causes that is that your soil is contaminated, the best thing you can do is put things in the back of the garden, put 'tatoes in, they clear that sort of thing up ... it's bacteria in the soil."' (Arthur)

In the account above, both Arthur and Tony described a wide range of benefits in line with sustainable place-making, including increasing skills and confidence, giving back to their local community and reducing the impacts of poverty. They also described how they felt isolated before the project, with isolation recognised as a mental health issue. The project also helped volunteers with more severe mental health issues. For 
example, another long-term volunteer, Paul, was discharged from community mental health care and used the volunteering at the farm as part of a regular weekly routine to help him with everyday life. He was referred to the project by the local NHS mental health team.

Interviewer: 'Does coming to the farm help you?'

Paul: 'Oh definitely, definitely, I've got somewhere to go, I can see people, ... before I had the farm, I had no one, I didn't see my family, I didn't have friends ... I was very lonely. But now I've got somewhere to go, even if it's only once a week, yes, I can look forward to it. So I think it's really helped, yes.'

Paul described how he would not have anywhere to go on a Wednesday if it wasn't for the community garden, helping him establish a routine. Paul also valued the therapeutic benefits of being outside in a nice environment and working at the community garden at the farm. The individual and community mental health benefits of access to nature described by Paul support the research by Ferris et al (2001) and Pitt (2014) and also link into the importance of access to green spaces and nature in reducing poverty for vulnerable people (Milbourne, 2012). "When you're here, you're almost in the countryside, and the countryside is very therapeutic, it's very serene, it calms you down, so it's very useful to get out into the community" (Paul).

The energy activities also helped a number of people although the outcomes were not as transformative or clearly described by participants. The project focused on helping residents save money through reducing energy usage and providing information on tariffs, pre-payment meters and the Warm Home Discount. By the end of the project, 450 energy monitors had been distributed and 72 households identified that they had saved approximately $\mathcal{E}^{2} 200$ per year on average. In addition to work with individual households, the project also worked with a sheltered housing provider to support its residents, many of whom were over 70 and lived in energy-inefficient housing. There were also some attempts to work with UA participants although this was not a systematic approach, only eight UA volunteers became involved and these did not include some of the more vulnerable volunteers such as Arthur, Tony and Paul.

However, the following two examples illustrate the potential benefits of being involved in both UA and energy activities. Barbara was a disabled grandmother and the project supported her to grow her own food and provided her with an energy monitor. Barbara had learnt about the project through her daughter who had attended some early UA training sessions. Support for growing her own food was really important to Barbara and the project helped her with advice, seeds, compost and raised beds: "Been really good, really good, because obviously with them putting my beds in, with my health issues, I could still do my veg. So all that side was absolutely fabulous" (Barbara).

Barbara grew a wide range of fruit and vegetables for enjoyment, health benefits and also providing good nutritious food for her and her grandchildren, involving her grandchildren in activities.

'My salad leaves, my tomatoes, and beans, loads of different types of beans and my grandchildren absolutely love beans ... and when you're actually planting up the kids love it ... they like to help to put it out, and they know that you don't just buy a packet - that's where it grows, so they enjoy it.' 
In terms of community energy, Barbara was already in receipt of the Warm Home Discount and had negotiated good tariff rates with her energy supplier before becoming involved with the project. However, Barbara estimated that using the energy monitor helped her save approximately $£ 180$ per year, mainly through reducing usage of an inefficient electric fire: "[I use the energy monitor] all the time, yes, because it surprises you, how much things cost ... we use to use an electric fire all the time, but when you look at how much it costs." Saving money proved essential. Barbara was worried about a state benefits reassessment by the DWP to move from the Disability Living Allowance (DLA) to the Personal Independence Payment (PIP). Even though Barbara was told she would qualify, she was also told there could be a four- to eightweek payment gap between her DLA support finishing and PIP starting, which could cause her significant financial difficulties.

Sarah was also involved in the family growing project and energy project. Sarah lived locally with her family, including her autistic son. She joined the family growing project so that she and her children could enjoy growing food, eat the fresh produce grown and also try to save some money: "I've always wanted to grow my own fruit and veg, but I kill things really quick! ... so I thought if I've got someone to help to help me and show me where I'm going wrong, and it's worked! I've had loads" (Sarah). Sarah also joined the energy activity and identified she saved around $£, 100$ per year through using the energy monitor to reduce the use of inefficient appliances such as the tumble dryer. She also received advice on tariffs and planned to switch from a pre-payment meter to direct debit, although at the time of research she could not afford the $£ 150$ payment needed to switch. Sarah felt that the project helped to reduce her vulnerability to poverty through providing an opportunity to reduce household costs. She described how she experienced fuel poverty in the past, but that she would not let that happen again.

'I used to live in a very, very, cold, draughty house, freezing cold house, it was a big house ... since I moved out I've never had a cold house because ... I won't let my kids, I'll go without to make sure the gas is paid - when you've been there, you've been in that poverty, you think I'll never do that again.'

\section{Considering long-term sustainability}

At the end of the project funding, the organisations continued to support some activities from their reserves, mainly by continuing to pay existing staff salaries. However, some key staff left and others became focused on new activities where funding could be obtained. For example, the lead charity focused on providing food parcels to vulnerable people, developing community allotments and working in schools in different areas across Hull. However, ongoing funding support was at a lower level than the BLF CLS funding, there was a time lag between the GP project finishing and receiving new funding and some of these activities were not in the GP project target area of east Hull and did not continue to work with the project participants. This meant that staff support for the community garden activities was scaled down and the project was unable to continue community outreach activities such as the family growing project. There was also no funding to continue the household energy project, which had tried to expand to work with registered social landlords in east Hull and residents in other areas. This affected the participants in different ways. The 
project had no ongoing connection to Barbara and Sarah who had been engaged in the family growing project and the energy project, and so it was not possible to track whether they had managed to sustain growing their own food or if Sarah managed to switch from a pre-payment meter to direct debit. The volunteers at the community garden did not feel able to continue on their own without staff support, for a range of reasons, including feeling fragile as a newly developed group, feeling they had limited capacity to manage activities and wanting a safe and secure environment for their activities. The limited staff support at the community garden meant that many volunteers reduced their attendance: for example, Arthur's attendance became more occasional and Paul stopped attending.

It was important for Arthur, Tony and Paul to maintain some connection to the staff and charities involved, as they really enjoyed being involved in activities and were worried about returning to feelings of isolation. In addition, both Arthur and Paul were worried about continuous uncertainty of state benefits and facing these challenges alone, and they were affected by the closure of the Hull College horticulture site, which became a Green Port Development training facility. Arthur also described how he used food from the different projects to improve his nutrition as he had recently developed diabetes. After the end of the project, both Tony and Arthur still volunteered in projects operated by the lead charity, including tree planting in schools and developing community allotments. A staff member identified how he said to Arthur he was sorry he could not start paying him for his work, but Arthur replied it was fine as he had never had the chance to be involved in such a positive project before. Paul became involved in a new community garden project operated by a small local charity, developed by former GP staff, and became responsible for being in charge of the site when senior officers were not there. He completed health and safety training, and was planning to take mental health-focused health and safety training, which was a major step forward for Paul who had previously stated he was not able to take training and qualifications due to a poor memory.

\section{Discussion: exploring outcomes and project sustainability}

The personal stories demonstrate that the project created social, health and economic benefits at both individual and community levels (Holland, 2004; Franklin and Marsden, 2015). The UA activity helped participants develop their skills and confidence and improve their health and wellbeing. Health and wellbeing impacts included a strong focus on improving mental health and helping to reduce isolation, and there was also evidence of adding fresh fruit and vegetables to some participants' diets. The UA activities also helped some participants to reduce their vulnerability to food poverty through reducing their vulnerability to benefit sanctions, as demonstrated by Arthur (Perry et al,2014).Although there were less clear social, health and wellbeing outcomes compared with the UA activities, the energy activities enabled some households to reduce vulnerability to fuel poverty through reducing energy usage and enabling participants to negotiate better tariffs or switch from pre-payment meters (Lorenc et al, 2013; Parkhill et al, 2015). Participants described how reducing costs helped them to improve their self-reliance, although the other impacts also contributed. As well as helping individuals and families, these outcomes can also be argued to have a community benefit. For instance, the UA activities enabled volunteers to help the wider community by developing the community garden and by broadening 
engagement to local families (Miller, 2015; Milligan and Fyfe, 2005). In addition, Parkhill et al (2015) describe reducing vulnerability to fuel poverty as increasing local community resilience.

There is a strong link from the UA activities to the concept of place-making, supporting arguments by Beilin and Hunter (2011) and Certomà and Tornaghi (2015). The UA activities were strongly based around the community garden, which provided a space for volunteers and participants to come together, enjoy gardening and access nature in a regular activity (Bhatti et al, 2009; Milbourne, 2012; Tornaghi, 2014). For many participants, memories of enjoying gardening as children (Bhatti et al, 2009), or the opportunity to involve their own children or grandchildren in new gardening activities, provided a platform for engagement. The volunteers also worked hard to improve the community garden, which they saw as improving the local community through providing a social space for volunteering, an attractive space for the local community to visit and a garden for growing produce for community activities such as the Feastival.Volunteers also described how they would help each other with their own private gardens or household tasks. There was less clear evidence of place-making from the energy activities, which had a household rather than a community focus and there was no opportunity to give back to the local community.

In terms of addressing criticisms of charity-led projects supporting the austerity measures and rollback of the state, the stories of Arthur, Tony and Paul in particular show that the project provided a unique opportunity to become involved in an innovative, proactive and positive project targeted at marginalised people and there were no alternatives in east Hull that suited their needs. The project was also improving the local area and therefore should be considered place-making rather than place-keeping (Certomà and Tornaghi, 2015; Mathers et al, 2017). However, staff felt additional pressures from supporting volunteers with more serious mental health problems, with no additional funding supporting people with mental health challenges A further criticism of sustainable place-making activities is their limited contribution to reducing global $\mathrm{CO}_{2}$ emissions (Chatterton and Cutler, 2008). The household energy activities did lead to a reduction in energy usage for some participants through using an energy monitor, which could reduce fossil-fuel emissions. However, overall levels of participation and reductions were very small and the project did not measure impacts on environmental $\mathrm{CO}_{2}$, in line with many other community-level projects with limited time and resources (Hargreaves et al, 2010; Mason and Montalto, 2015). The UA and volunteering activities could have also benefited the environment through gardening, supporting a local food network and other smaller activities such as tree planting and building bat and bird boxes. While staff and participants viewed any environmental contribution as very small in scale, they strongly voiced the importance of these actions in contributing in some way to global-level environmental concerns and as a strong tool to engage people in future environmental actions.

Sustainable place-making also needs to consider 'sustainability' in terms of the sustainability of outcomes (Seghezzo, 2009). For example, long-term sustainability is essential to provide security for improvements to marginalised people's lives, as they are most at risk of negative changes such as increasing isolation, punitive state benefit policies and financial insecurity. Long-term sustainability is also essential to embed environmental improvements. However, in this case study the GP project went from $\mathcal{L}_{1} 1$ million funding over three years to no funding at the beginning of 2016 , 
which critically affected long-term sustainability (IVAR, 2016). The project staff felt unable to plan for long-term sustainability within the three-year project timeframe. The community garden and volunteer team did not become established until year two and the family growing project started in year three. It was also difficult to know in advance if these activities would be successful and worth supporting in the long term. Despite the challenges, the strong commitment from the organisations, staff and volunteers to continue the community gardening and volunteering activities where possible, and also innovate new activities, provided a platform for some continuation (Purcell and Tyman, 2015; van der Jagt et al, 2017), albeit at a smaller scale. In addition, land was available for these activities including continued access to the community garden (Purcell and Tyman, 2015; St Clair et al, 2017). However, despite the best efforts of the organisations, staff and volunteers, the lack of long-term sustainability meant that the outcomes were fragile.

\section{Nurturing shoots: overall conclusions}

Sustainable place-making emerges as a strong framework for critically analysing the GP project as the project worked towards environmental, social and economic improvements in the local community. In addition, the research demonstrates that sustainable place-making can have clear health, social and economic outcomes for marginalised people in deprived communities. The project helped people to access nature, improve their health and wellbeing, reduce isolation, improve their skills and confidence, work with others with enjoyment and give back to their local communities. The project also helped reduce vulnerability to fuel poverty and food poverty including through reducing vulnerability to benefit sanctions. Although outcomes were more transformative for UA activities than for the energy activities, and very few participants engaged in both, there were some benefits of developing more than one sustainable place-making activity. In terms of environmental outcomes, the project did not demonstrate any reductions in $\mathrm{CO}_{2}$ emissions; however, the project showed how involvement in local environmental activities, including both gardening and biodiversity, could help benefit and also engage residents.

However, the charities leading the project were not able to ensure long-term sustainability within the three-year project timeframe (IVAR, 2016). This meant that outcomes for marginalised people were fragile and, relating this conclusion back to the title of the article, the project had developed 'shoots' in terms of improvements to vulnerable people's lives and environmental benefits, but it was also important that participants were not left unsupported at this early stage. There was a need for continued financial support to help plan and work towards long-term sustainability. To achieve this, a key recommendation, grounded in the reality of the GP project and aimed at project funders and project managers, is for reflexive funding to enable effective activities to be continued after initial funding periods finish. This recommendation is problematic as what is considered successful and who decides will be contested. However, in this case study, it is argued that there should have been immediate further funding to support the community garden and the volunteer team at existing staffing levels, and this could then be used as a basis for continued community outreach. There could have also been limited funding for a targeted approach to enable the UA participants to receive the household energy support, and this would have also provided time to explore social, economic and environmental impacts further and 
consider new energy projects. An open and transparent conversation would also allow discussion of where additional support could be required, such as supporting participants with severe mental health challenges. In contrast, other unsuccessful activities would not be continued. Any further funding should also focus on building skills and access to wider support networks (Franklin et al,2011), with an aim to reduce dependency on funding in the long term. This long-term approach would require effective joint working between charities, communities, funding organisations and local authorities (Franklin and Marsden, 2015; van der Jagt et al, 2017). This could be possible in Hull due to its active sustainable place-making efforts particularly around UA and community gardening.

\section{Conflict of interest}

The author declares that there is no conflict of interest.

\section{References}

Aiken, G. (2012) Community transitions to low carbon futures in the transition towns network (TTN), Geography Compass, 6(2): 89-99. doi: 10.1111/j.1749-8198.2011.00475.x

Atkinson, D. (2008) The heritage of mundane places, in B. Graham and P. Howard (eds) The Ashgate Research Companion to Heritage and Identity, Aldershot: Ashgate, pp 381-95.

Baker, L.E. (2004) Tending cultural landscapes and food citizenship in Toronto's community gardens, Geographical Review, 94(3): 305-25. doi: 10.1111/j.19310846.2004.tb00175.x

Beilin, R. and Hunter,A. (2011) Co-constructing the sustainable city: how indicators help us 'grow' more than just food in community gardens, Local Environment, 16(6): 523-38. doi: 10.1080/13549839.2011.555393

Bhatti, M., Church,A., Claremont,A. and Stenner, P. (2009) I love being in the garden: enchanting encounters in everyday life, Social and Cultural Geography, 10(1):61-76. doi: 10.1080/14649360802553202

Big Lottery Fund (2018) About the big lottery fund, https://www.biglotteryfund. org.uk/about-big/our-approach/about-big-lottery-fund

Certomà, C. and Tornaghi, C. (2015) Political gardening: transforming cities and political agency, Local Environment, 20(10): 1123-31.

Chatterton, P. and Cutler, A. (2008) The rocky road to a real transition: the transition towns movement and what it means for social change, http://trapese.clearerchannel. org/resources/rocky-road-a5-web.pdf

Colquhoun, D., Wright, N., Pike, J. and Gatenby, L. (2008) Evaluation of Eat Well Do Well: Kingston Upon Hull's School Meal Initiative, Centre for Educational Studies, Institute of Learning, Hull: University of Hull.

Crane,A.,Viswanathan, L. and Whitelaw, G. (2013) Sustainability through intervention: a case study of guerrilla gardening in Kingston, Ontario, Local Environment, 18(1): 71-90. doi: 10.1080/13549839.2012.716413

Creamer, E. (2015) The double-edged sword of grant funding: a study of communityled climate change initiatives in remote rural Scotland, Local Environment, 20(9): 981-99. doi: 10.1080/13549839.2014.885937 
Dagdeviren, H., Donoghue, M. and Promberger, M. (2016) Resilience, hardship and social conditions, Journal of Social Policy, 45(1): 1-20. doi: 10.1017/ S004727941500032X

Dale,A., Ling, C. and Newman, L. (2008) Does place matter? Sustainable community development in three Canadian communities, Ethics, Place and Environment, 11(3): 267-81. doi: 10.1080/13668790802559676

FareShare (2015) Hull food charity reveals huge rise in demand from struggling families, http://faresharehullhumber.org/hull-food-charity-reveals-hugerise-in-demand-from-struggling-families

Ferris, J., Norman, C. and Sempik,J. (2001) People, land and sustainability: community gardens and the social dimension of sustainable development, Social Policy $\mathcal{E}$ Administration, 35(5): 559-68.

Franklin,A. and Marsden,T. (2015) (Dis)connected communities and sustainable placemaking, Local Environment, 20(8): 940-56. doi: 10.1080/13549839.2013.879852

Franklin, A., Newton, J., Middleton, J. and Marsden, T. (2011) Reconnecting skills for sustainable communities with everyday life, Environment and Planning A, 43(2): 347-62. doi: 10.1068/a426

Hargreaves, T., Nye, M. and Burgess, J. (2010) Making energy visible: a qualitative field study of how householders interact with feedback from smart energy monitors, Energy Policy, 38(10): 6111-19. doi: 10.1016/j.enpol.2010.05.068

Heynen, N., Kaika, M. and Swyngedouw, E. (eds) (2006) In the Nature of Cities: Urban Political Ecology and the Politics of Urban Metabolism, London:Taylor \& Francis.

Holland, L. (2004) Diversity and connections in community gardens: a contribution to local sustainability, Local Environment, 9(3): 285-305. doi: $10.1080 / 1354983042000219388$

Horlings, L.G. (2015) Values in place: a value-oriented approach toward sustainable place-shaping, Regional Studies, Regional Science, 2(1): 257-74. doi: 10.1080/21681376.2015.1014062

IVAR (Institute forVoluntary Action Research) (2016) Thinking About Sustainability, London: IVAR, https://www.ivar.org.uk/wp-content/uploads/2016/11/ IVAR011-Sustainability-Report_V6.pdf

Jean, M. (2015) The role of farming in place-making processes of resettled refugees, Refugee Survey Quarterly, 34(3): 46-69. doi: 10.1093/rsq/hdv007

Jonas,A.E.G.,Wurzel, R.K.W., Monaghan, E. and Osthorst,W. (2016) Climate change, the green economy and reimagining the city: the case of structurally disadvantaged European maritime port cities, unpublished, draft typescript.

Lorenc, A., Pedro, L., Badesha, B., Dize, C., Fernow, I. and Dias, L. (2013) Tackling fuel poverty through facilitating energy tariff switching: a participatory action research study in vulnerable groups, Public Health, 127(10): 894-901. doi: 10.1016/j. puhe.2013.07.004

Mason, E. and Montalto, F.A. (2015) The overlooked role of New York City urban yards in mitigating and adapting to climate change, Local Environment, 20(12): 1412-27. doi: 10.1080/13549839.2014.907249

Mathers, A., Dempsey, N. and Molin, J.F. (2015) Place-keeping in action: evaluating the capacity of green space partnerships in England, Landscape and Urban Planning, 139: 126-36. doi: 10.1016/j.landurbplan.2015.03.004 
Milbourne, P. (2012) Everyday (in) justices and ordinary environmentalisms: community gardening in disadvantaged urban neighbourhoods, Local Environment, 17(9): 943-57. doi: 10.1080/13549839.2011.607158

Miller, W.M. (2015) UK allotments and urban food initiatives: (limited?) potential for reducing inequalities, Local Environment, 20(10): 1194-214. doi: 10.1080/13549839.2015.1035239

Milligan, C. and Fyfe, N.R. (2005) Preserving space for volunteers: exploring the links between voluntary welfare organisations, volunteering and citizenship, Urban Studies, 42(3): 417-33. doi: 10.1080/00420980500034884

ONS (Office for National Statistics) (2015) The English Indices of Deprivation 2015: National Statistics Statistical Release 2015: Department for Communities and Local Government, London: GOV.UK, https://www.gov.uk/government/uploads/system/ uploads/attachment_data/file/465791/English_Indices_of_Deprivation_2015_-_ Statistical_Release.pdf

Parkhill, K.A., Shirani, F., Butler, C., Henwood, K.L., Groves, C. and Pidgeon, N.F. (2015) We are a community [but] that takes a certain amount of energy: exploring shared visions, social action, and resilience in place-based communityled energy initiatives, Environmental Science and Policy, 53: 60-9. doi: 10.1016/j. envsci.2015.05.014

Pearsall, H., Pierce, J. and Krueger, R. (2012) Whither Rio +20?: demanding a politics and practice of socially just sustainability, Local Environment, 17(9): 935-41. doi: 10.1080/13549839.2012.724899

Perry, J., Williams, M., Sefton, T. and Haddad, M. (2014) Emergency Use Only: Understanding and Reducing the Use of Food Banks in the UK, Oxford: Oxfam GB.

Pierce, J., Martin, D.G. and Murphy, J.T. (2011) Relational place-making: the networked politics of place, Transactions of the Institute of British Geographers, 36(1): 54-70. doi: 10.1111/j.1475-5661.2010.00411.x

Pitt, H. (2014) Therapeutic experiences of community gardens: putting flow in its place, Health and Place, 27: 84-91. doi: 10.1016/j.healthplace.2014.02.006

Platt, E. (2011) The city on the edge of the world, New Statesman, 31 October, https:// www.newstatesman.com/society/2011/10/hull-city-reckitt-father-road

Porter, M., Iddenden, R.S. and Greene, T. (2015) HULL JSNA Toolkit Release 5: Housing, Environment and Social Care.

Purcell, M. and Tyman, S.K. (2015) Cultivating food as a right to the city, Local Environment, 20(10): 1132-47. doi: 10.1080/13549839.2014.903236

Seghezzo, L. (2009) The five dimensions of sustainability, Environmental Politics, 18(4): 539-56. doi: 10.1080/09644010903063669

Seyfang, G., Park, J.J. and Smith, A. (2013) A thousand flowers blooming? An examination of community energy in the UK, Energy Policy, 61: 977-89. doi: 10.1016/j.enpol.2013.06.030

St Clair, R.S., Hardman, M., Armitage, R.P. and Sherriff, G. (2017) The trouble with temporary: impacts and pitfalls of a meanwhile community garden in Wythenshawe, South Manchester, Renewable Agriculture and Food Systems, 1-10.

Starkey, D.J., Atkinson, D., McDonagh, B., McKeon, S. and Salter, E. (2017) Hull: Culture, History, Place, Liverpool: Liverpool University Press.

Stephenson, J., Barton, B., Carrington, G., Gnoth, D., Lawson, R. and Thorsnes, P. (2010) Energy cultures: a framework for understanding energy behaviours, Energy Policy, 38(10): 6120-29. doi: 10.1016/j.enpol.2010.05.069 
Sustainable Food Cities (2017) City Information: Hull Food Partnership. http:/t sustainablefoodcities.org/findacity/cityinformation/userid/37

Tornaghi, C. and Van Dyck, B. (2015) Research-informed gardening activism: steering the public food and land agenda, Local Environment, 20(10): 1247-64. doi: 10.1080/13549839.2014.949643

Tornaghi, S. (2014) Critical geography of urban agriculture, Progress in Human Geography, 38(4): 551-67. doi: 10.1177/0309132513512542

van den Bosch, M. and Sang,Å.O. (2017) Urban natural environments as nature-based solutions for improved public health-a systematic review of reviews, Environmental Research, 158: 373-84. doi: 10.1016/j.envres.2017.05.040

van der Jagt,A.P., Szaraz, L.R., Delshammar,T., Cvejić, R., Santos, A., Goodness, J. and Buijs, A. (2017) Cultivating nature-based solutions: the governance of communal urban gardens in the European Union, Environmental Research, 159: 264-75. doi: 10.1016/j.envres.2017.08.013

White, R. and Stirling,A. (2013) Sustaining trajectories towards sustainability: dynamics and diversity in UK communal growing activities, Global Environmental Change, 23(5): 838-46. doi: 10.1016/j.gloenvcha.2013.06.004 


\section{AUTHOR QUERIES}

\section{Author Please Answer all Queries}

AQ1 - not in the references - please supply - or did you mean to cite 2015, which is in the References?

AQ2-not in the references - please supply - or did you mean to cite 2015, which is in the References?

AQ3 - It is unclear as to why DWP staff would be less supportive when it is the college that was affected by their needing to sign on - is the wording correct?

AQ4-Mathers et al isn't in the references - please supply - or did you mean to cite 2015, which is in the References?

AQ5-The rest of the sentence is a little unclear - please check the wording and amend as necessary.

AQ6-Not cited. Is it ok to delete the reference? If not, please indicate where it should be cited.

AQ7-The link doesn't work. Is it possible to find another one? 